\title{
Discovering Language Properties through Corpus-Based Dictionary Data Analysis
}

\author{
Paul A. Lyddon \\ Osaka Jogakuin College \\ doi: http://dx.doi.org/10.7820/vli.v06.2.Lyddon
}

\begin{abstract}
To reveal underlying patterns in real language use, linguists have increasingly come to rely on corpus analyses, involving the evaluation of statistical frequencies in generally sizable bodies of natural linguistic data. However, accessing and analyzing large samples of raw language is neither always practical nor even truly necessary, especially in cases pertaining to structural characteristics. In fact, the requisite data can oftentimes be gleaned from a state-of-the-art (i.e., corpus-based) dictionary. Moreover, given the widespread availability of easily searchable electronic dictionaries nowadays, almost any language teacher or learner can use one to answer a number of these types of queries. This paper illustrates this claim with a step-by-step analysis of corpus-based dictionary data for the purpose of formulating the sound-symbol relations in English words with vowels preceding $-g h$.
\end{abstract}

Within the discipline of corpus linguistics, a "corpus" is traditionally defined as "a large and principled collection of natural texts" (Biber, Conrad, \& Reppen, 1998, p. 4). Moreover, the texts it comprises should have been spoken or written for some authentic communicative purpose (Gries, 2009), thus technically disqualifying the contents of a dictionary from consideration as a corpus. Nevertheless, given the large and principled bodies of lexical data dictionaries contain, they can still serve as convenient tools for evaluating statistical frequencies to reveal structural linguistic properties that do not necessarily require examples of contextualized utterances, and the findings can subsequently be used to inform second language (L2) pedagogy. Lyster (2006), for instance, culled and analyzed 9,961 nouns from the 20,000-word French children's dictionary Le Robert Junior Illustré to discover patterns of grammatical gender associated with various orthographic endings (e.g., all nouns ending in /ø/ are masculine, except when spelled -eue, as in banlieue "suburbs," in which case they are always feminine), and then went on to suggest ways to use these regular tendencies to help L2 French learners master this notoriously difficult aspect of the language.

In addition to elucidating grammatical structures, dictionary data analyses can also be used to uncover phonological patterns. In Japanese, for instance, there is a phenomenon known as rendaku, which results in the voicing of a normally voiceless obstruent at the start of a non-initial element of a compound (e.g., uta "song" + koe "voice" $\rightarrow$ uta.goe "singing voice"). While a number of systematic 
rules such as Mootori-Lyman's Law (Lyman, 1894; Motoori, 1822) and the RightBranch Condition (Otsu, 1980) help to explain the absence of rendaku in many compounds (e.g., hana.taba "bouquet" and roodoo.kumiai "labor union"), the phenomenon remains less than entirely predictable. For this reason, starting with the native Japanese word lists in Martin (1987), Irwin, Miyashita, and Russell (2017) compiled a database of over 34,000 rendakuable compounds and tagged them according to their rendaku status as given in two major dictionaries, Kojien, 6th ed., and Kenkyüsha's New Japanese-English Dictionary Digital Supplemented Edition.

Previous versions of the database have not only generated research on the prevalence of rendaku under various conditions, such as in compounds with at least one element three or more moras in length (e.g., nuri.gusuri "salve" or arai. guma "raccoon"; Irwin, 2016a), but they have also led to the identification of 68 non-initial elements (e.g., kamo "duck" and tera "temple") that always undergo rendaku and 18 others (e.g., shio "tide" and tsuchi "soil") that never do (Irwin, 2016b). As 1,809 of the 9,779 compounds appearing in both database dictionaries and unequivocally exhibiting or not exhibiting rendaku end in either a submissive or an immune element, remembering the immunity status of a mere 86 out of the 1,201 total unique non-initial elements would enable L2 Japanese learners to accurately predict the presence or absence of rendaku in nearly $20 \%$ of all compounds that they would most likely ever encounter but that are not subject to either Mootori-Lyman's Law or the Right-Branch Condition.

Though the Rendaku Database took years to compile, even a readily available standard electronic dictionary can be used to uncover unconscious linguistic patterns, provided the data it contains are suitably balanced and representative of the target linguistic phenomenon in its entirety.

There is a whimsical poem attributed to T.S. Watt (Taylor \& Taylor, 1983), entitled "Brush Up Your English: Hints on Pronunciation for Visiting Foreigners," which starts like this:

I take it you already know

Of tough and bough and cough and dough?

Some may stumble, but not you,

On hiccough, thorough, slough and through?

It later goes on to exemplify numerous other inconsistencies between English spelling and pronunciation before finishing with the amazing fact that the poet (and presumably the L1 English-speaking reader) had mastered the language by the age of five. L2 English learners, on the other hand, may not share Watt's sense of humor in light of the seemingly bewildering variety of pronunciations of just this single four-letter combination, -ough. They need not necessarily conclude, however, that they simply must learn the pronunciation of each word individually, for of the eight given instances of words ending in -ough, only six actually correspond to a unique pronunciation (see Table 1). Although the phonemic transcriptions here represent Standard American English pronunciations, the number of categories and the words that constitute them, here and elsewhere below, should be the same for other standard varieties of English as well. 
Table 1. Pronunciations of -ough in Watt Poem

\begin{tabular}{cccccc}
\hline$/$ Af $/$ & $/ \mathrm{au} /$ & $/ \mathrm{ff} /$ & $/ \mathrm{o} /$ & $/ \wedge \mathrm{p} /$ & $/ \mathrm{u} /$ \\
\hline tough, slough & bough & cough & dough, thorough & hiccough & through \\
\hline
\end{tabular}

Next we may ask whether and when L2 English learners (in my case, in Japan) are ever likely to encounter these words in their studies or their work life. To answer this question, I have chosen Minamide's (2014) Genius EnglishJapanese Dictionary, 5th ed. (hereafter G5). Not only are Genius dictionaries now based a 20 million-word half-written, half-spoken corpus (Taishūkan, 2003), but also they have always ranked the headwords they contain by level of importance (Taishūkan, 2009). For the 4th edition, the editors performed a major revision of the rankings, comparing the words in other commercially available dictionaries with the 6,300-word British National Corpus frequency list and their own privately developed 62,500-word frequency list to propose initial levels (Taishūkan, 2006), which they then adjusted to take into account the necessary vocabulary size to handle high school textbooks and university entrance exams (Taishūkan, 2009).

At present, the rankings of the roughly 84,250 headwords in the $G 5$ are as follows (Minamide, 2014):

A rank: Junior high school level (approx. 1,150 words)

B rank: High school level (approx. 3,150 words)

$\mathrm{C}$ rank: University and working world level (approx. 5,300 words)

D rank: Others (approx. 74,650 words)

A figure of $95 \%$ lexical coverage has been shown to be sufficient for good L2 listening comprehension (Van Zeeland \& Schmitt, 2013) as well as adequate reading comprehension (Laufer \& Ravenhorst-Kalovski, 2010). According to thresholds suggested by Chujo (2004), the current B rank should, thus, provide this sufficient coverage for junior and senior high school textbooks, Eiken Level 2, TOEIC, the National Center Test, and most university entrance exams. Moreover, the $\mathrm{C}$ rank should do likewise for Eiken Level 1 and TOEFL. While some language educators might argue whether the approved textbooks and official qualification tests currently in use in Japan truly reflect the kinds of English we should actually teach, the point here is not to endorse national curricular decisions that exceed most classroom teachers' immediate sphere of control but rather to suggest how to more responsibly teach what we are now responsible for teaching. As such, the contents of the $G 5$ do indeed appear to be representative of the necessary lexicon for most Japanese learners of English and therefore appropriate for the purpose of answering our question. Table 2 now reflects the distribution of Watt's examples by level of importance.

This reorganization leads us to discover that, at least for the words in the poem, two pronunciations of - ough (i.e., /au/ and $/ \Lambda \mathrm{p} /$ ) are essentially irrelevant, as only the most advanced of learners are liable to run into them. However, as the object here is to uncover underlying patterns, I next conduct a wildcard search (i.e., ough) of the $G 5$ on a Casio XD-G20000 electronic dictionary to produce a list 
Table 2. Watt Poem -ough Words by Rank in G5

\begin{tabular}{|c|c|c|c|c|c|c|}
\hline \multirow[t]{2}{*}{ Rank } & \multicolumn{6}{|c|}{ pronunciation of -ough } \\
\hline & I^f/ & lau/ & lof/ & $10 /$ & $/ \wedge \mathrm{p} /$ & $/ \mathrm{u} /$ \\
\hline$A$ & & & & & & through \\
\hline$B$ & tough & & cough & thorough & & \\
\hline C & & & & & & \\
\hline $\mathrm{D}$ & slough & bough & & dough & hiccough & \\
\hline
\end{tabular}

Table 3. Words Ending in -ough Through Tertiary-Level Rank in G5

\begin{tabular}{lcccccc}
\hline Rank & \multicolumn{7}{c}{ pronunciation of -ough } \\
\cline { 2 - 7 } & IAf/ & /au/ & /of/ & /o/ & /^p/ & /u/ \\
\hline A & enough & - & - & although, though & - & through \\
B & tough, rough & - & cough & thorough & - & - \\
C & - & plough & - & borough & - & - \\
\hline
\end{tabular}

Table 4. Important Words Ending in -gh Pronounced /f/

\begin{tabular}{|c|c|c|c|}
\hline \multirow[t]{2}{*}{ Rank } & \multirow{2}{*}{$\begin{array}{c}a u \\
æ /\end{array}$} & \multicolumn{2}{|c|}{ ou } \\
\hline & & $|\Lambda|$ & / / / \\
\hline$A$ & laugh & enough & - \\
\hline$B$ & - & tough, rough & cough \\
\hline C & - & - & - \\
\hline
\end{tabular}

of all the most important words ending in - ough that Japanese learners of English are most likely to encounter, the results of which are shown in Table 3.

In summary, there are really only 10 such words. Moreover, $/ \Lambda \mathrm{p} /$ is indeed never used, /au/ is only used once, in "plough," which has the alternate spelling "plow," and /of/ and /u/, though both deemed important in secondary-level English learning, are truly exceptional. Four words end in /o/, but only one fewer ends with $-g h$ pronounced as /f/, which raises an additional question, namely that of when $-g h$ is silent and when it is not. A subsequent wildcard search using $\sim g h$ reveals that "laugh" is the only other word ending in $-g h$ pronounced as /f/. Thus, we can now make an exhaustive list of the five target words, given in Table 4.

We also discover that only two other vowel spellings- $i$, and $e i-$ ever appear before a final $-g h$, and that the pronunciations of these sounds are always /ai/ and lei/, respectively. Table 5 gives a summary of the five words in question.

Adding in the words that end in - ough where the $-g h$ is silent yields Table 6, which includes a total of 11 words. Thus, the following tendencies now become clear. First, in over two thirds of words ending in $-g h$, the ending is silent. Second, only four vowel spellings ever precede final $-g h$, and of those, only ou leads to any variation in pronunciation.

Admittedly, 16 words is a relatively small return on the effort invested thus far, but these tendencies encompass a much greater lexicon if we now expand our 
Table 5. Words Containing Vowel Spellings Besides au and ou Before $-g h$

\begin{tabular}{lcc}
\hline Rank & $i$ & ei \\
\cline { 2 - 3 } & /ai/ & /ei/ \\
\hline A & high & - \\
B & sigh & weigh \\
C & thigh & sleigh \\
\hline
\end{tabular}

Table 6. Words Ending in Silent $-g h$

\begin{tabular}{lcccccc}
\hline Rank & $i$ & & ei & & \multicolumn{3}{c}{ ou } \\
\cline { 2 - 3 } \cline { 5 - 7 } & lai/ & lei/ & lo/ & /u/ & /au/ \\
\hline A & high & - & although, though & through & - \\
B & sigh & weigh & borough, thorough & - & - \\
C & thigh & sleigh & - & - & - & plough \\
\hline
\end{tabular}

search to include not only words that end in $-g h$ but also those that contain at least one additional letter thereafter (e.g., ??gh?, ??gh??). We find three more words in which - gh is pronounced /f/: "draught," "laughter," and "roughly," all high schoollevel words, the first of which has an alternate popular spelling "draft" and the latter two of which belong to word families we have already identified. We also find that when -augh is not pronounced /æf/, it is always pronounced / $/$, which is the majority of all cases. Finally, we discover that there is only one instance of -eigh pronounced as something other than /ei/, which is "height." As the point now is not only to discover the phonological patterns for orthographic combinations but also to demonstrate their fruitfulness, Table 7 shows the most important words containing post-vocalic silent $-g h \sim$.

The consonant digraph - $g h$ only appears after five different vowel spellings: $a i, i, e i, a u$, and $o u$. It is always silent after $a i, i$, and $e i$, even if other letters (e.g., $-t,-t h)$ act to close the syllable, and the pronunciations of these vowel spellings in combination with $-g h$ are regular: $a i$, which only appears in the "straight" word family is pronounced /ei/, $i$ is always /ai/ (e.g., "sigh," "sight"), and $e i$, like $a i$, is always /ei/ (e.g., "weigh," "weight"), the only exception being "height", where it is lai/ as in "high."

After $a u,-g h$ is also almost always silent, with only three exceptions: "laugh(ter)" /læf(tər)/ and "draught" /dræft/ (also spelled "draft"). Moreover, other than in these exceptions, au before $-g h$ is always pronounced /o/ (e.g., "caught," "naughty," "daughter").

Other than "laugh(ter)" and "draught," there are only other five common words in which $-g h$ is pronounced as /f/, and in each case, it is preceded by ou, which can be pronounced $/ \Lambda /$ (i.e., "enough," "tough," "rough(ly)") or / / (i.e., "cough"). Otherwise, even after ou, $-g h$ is silent, and the ou is pronounced /o/ (e.g., "though," "thorough"), with only two exceptions: "through"/ $/ \mathrm{ru} /$ and "plough" /plau/ (also spelled "plow"). When -ough is followed by $-t$, with the exception of "drought" /draut/, it is always pronounced /ot/ (e.g., "ought," "bought"). 


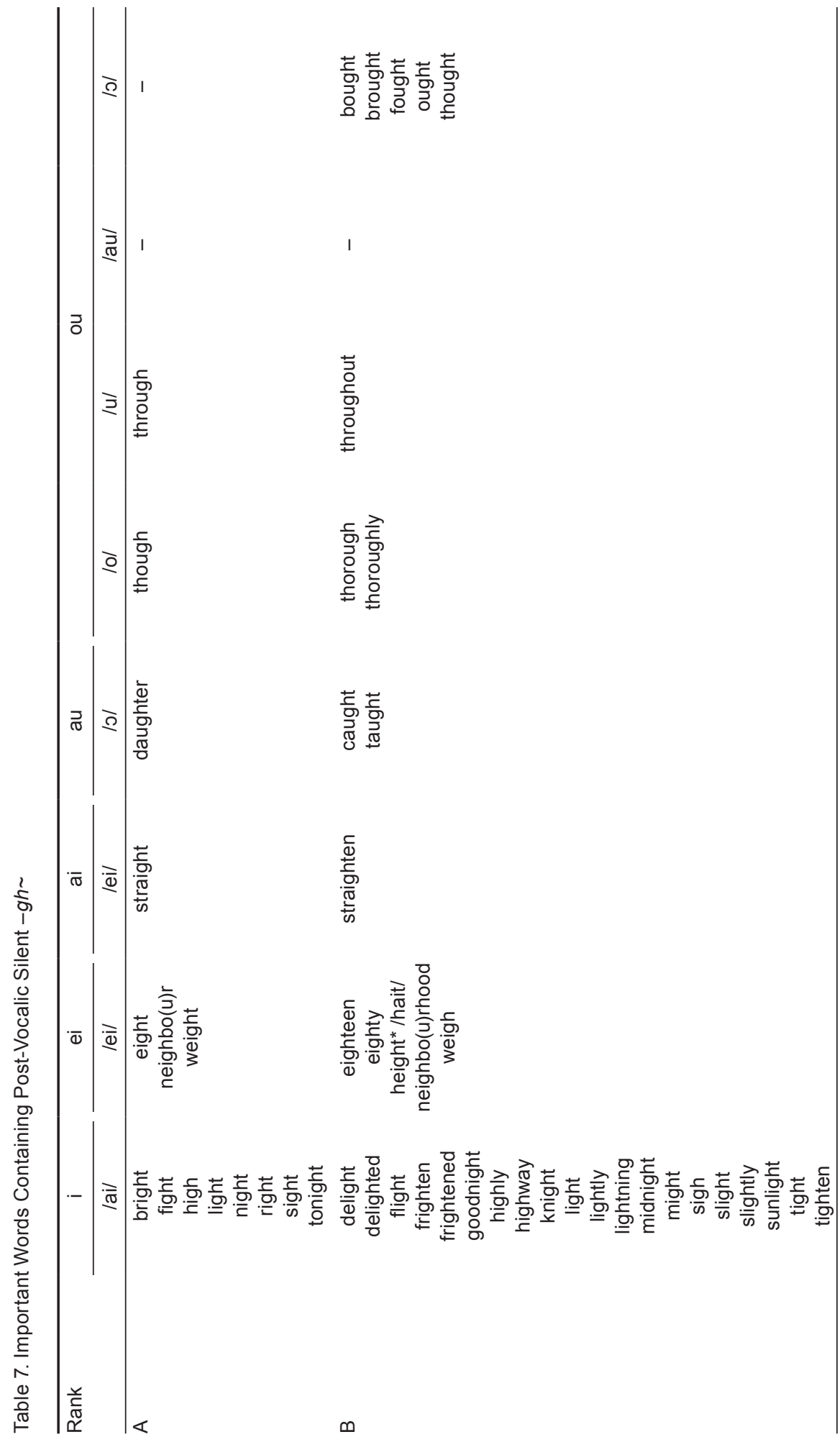

Vocabulary Learning and Instruction, 6 (2), 61-70. 


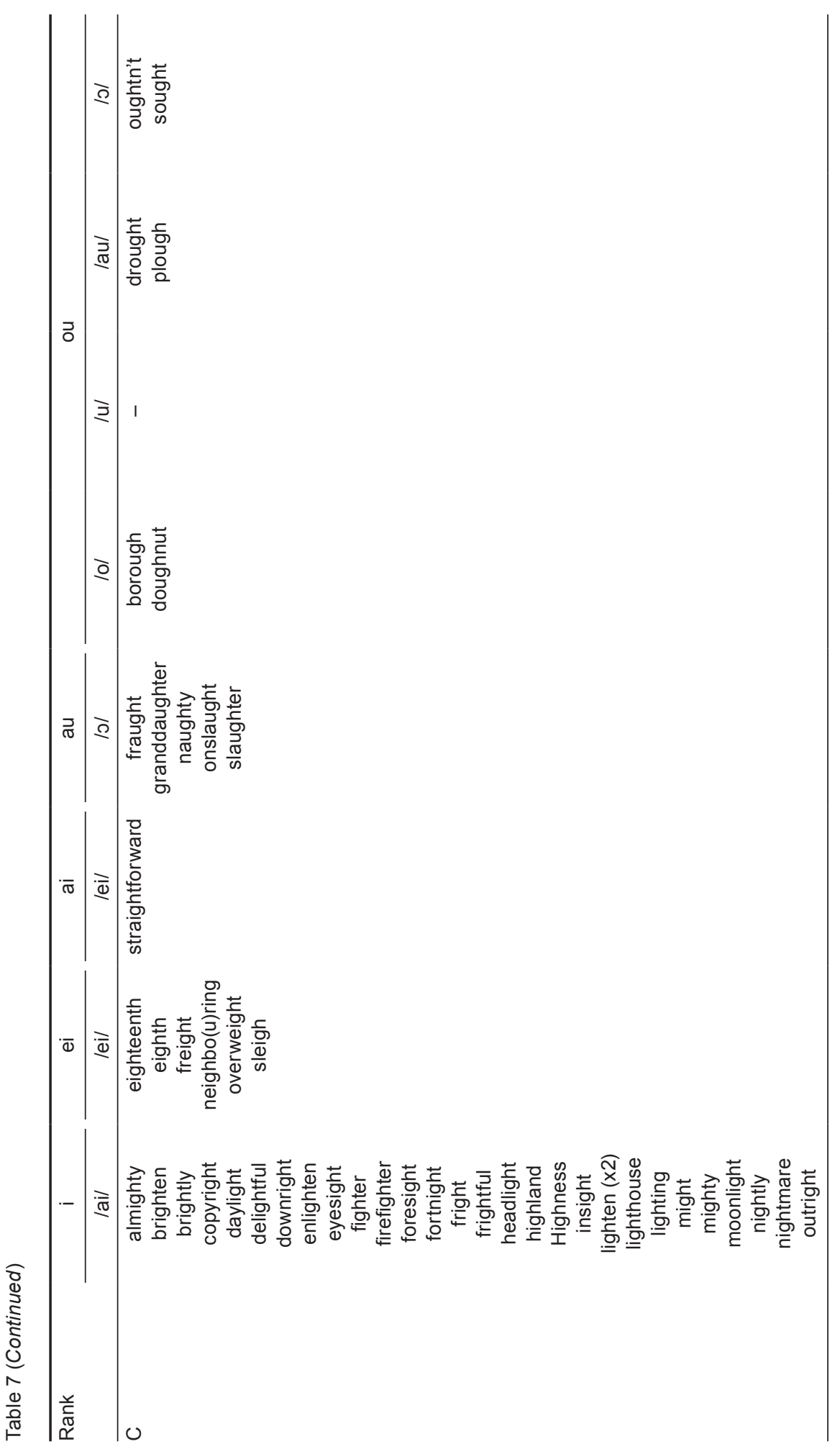




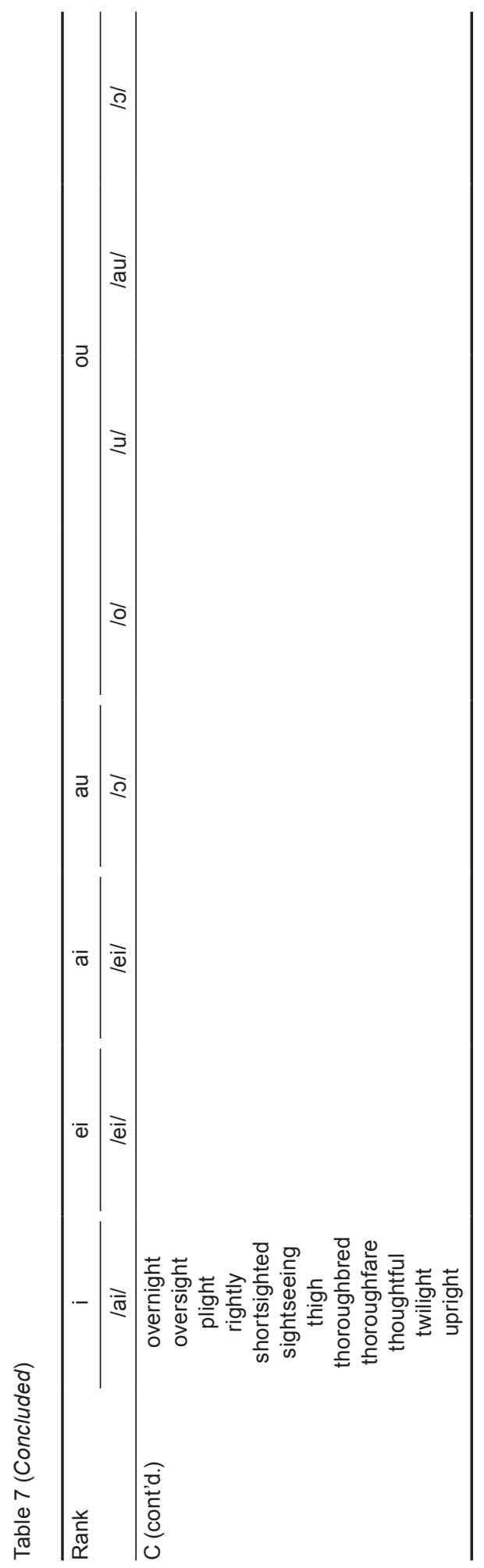


In the end, we discern that there are six basic patterns, which can be described as follows:

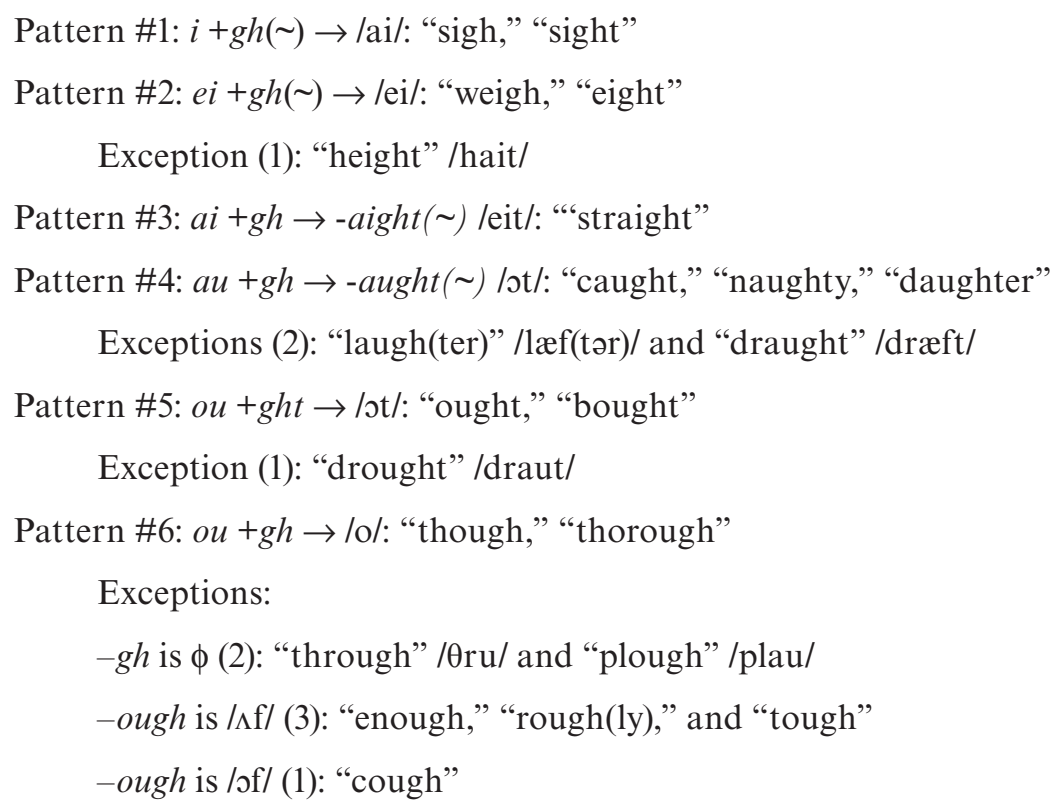

Of course, Japanese learners may still have difficulty producing $/ \Lambda /$ as well as distinguishing / $/$ from /o/. Nevertheless, by learning just 6 patterns and a mere 10 exceptions, they should at least potentially be able to identify the target pronunciations of vowel sounds before - $g h$ in all 118 of the most important words up to the 9,600-word level.

\section{Conclusion}

Given the modern standard of compiling dictionaries on the basis of corpus data and the widespread availability of powerful digital tools to facilitate their exploitation, dictionary analyses, unconventional though they may be, present a viable option for discovering unconscious lexical patterns in cases where large samples of raw language data are either impractical or unnecessary. As a superior alternative to both demoralizing agnosticism and faulty intuition, the findings they yield can then be used to inform, motivate, and improve L2 teaching and learning.

\section{References}

Biber, D., Conrad, S., \& Reppen, R. (1998). Corpus linguistics: Investigating language structure and use. New York, NY: Cambridge University Press.

Chujo, K. (2004). Measuring vocabulary levels of English textbooks and tests using a BNC lemmatised high frequency word list. In J. Nakamura, N. Inoue, \& T. Tabata (Eds.), English corpora under Japanese eyes (pp. 
231-249). Amsterdam, The Netherlands: Rodopi. Retrieved from http:// www5d.biglobe.ne.jp/chujo/eng/data/rodopi.pdf

Gries, S.T. (2009). What is corpus linguistics? Language and Linguistics Compass, 3, $1225-1241$.

Irwin, M. (2016a). Rosen's rule. In T.J. Vance \& M. Irwin (Eds.), Sequential voicing in Japanese: Papers from the NINJAL Rendaku Project (pp. 107-117). Amsterdam, The Netherlands: John Benjamins.

Irwin, M. (2016b). The Rendaku Database. In T.J. Vance \& M. Irwin (Eds.), Sequential voicing in Japanese: Papers from the NINJAL Rendaku Project (pp. 79-106). Amsterdam, The Netherlands: John Benjamins.

Irwin, M., Miyashita, M., \& Russell, K. (2017). The Rendaku Database v3.1. Retrieved from http://www-h.yamagata-u.ac.jp/ irwin/site/Rendaku_Database.html

Laufer, B., \& Ravenhorst-Kalovski, G. C. (2010). Lexical threshold revisited: Lexical coverage, learners' vocabulary size and reading comprehension. Reading in a Foreign Language, 22, 15-30.

Lyman, B. (1894). The change from surd to sonant in Japanese compounds. Philadelphia, PA: Oriental Club of Philadelphia.

Lyster, R. (2006). Predictability in French gender attribution: A corpus analysis. Journal of French Language Studies, 16, 69-92.

Martin, S. (1987). The Japanese language through time. New Haven, CT: Yale University Press.

Minamide, K. (Ed.). (2014). Genius ei-wa jiten dai-5 han [Genius English-Japanese Dictionary (5th ed.)]. Tokyo, Japan: Taishūkan.

Motoori, N. (1822). Kojiki den [Commentary on the Kojiki]. Edo: Maegawa Rokuzaemon.

Otsu, Y. (1980). Some aspects of rendaku in Japanese and related problems. In Y. Otsu \& A. Farmer (Eds.), Theoretical issues in Japanese linguistics (pp. 207-227). MIT Working Papers in Linguistics \#2. Cambridge, MA: MIT Department of Linguistics and Philosophy.

Taishūkan (2003, November). Genius Captain Departure: Genius Jisho Question Box. G.C.D. Eigo Tsüshin, no. 34, pp. 22-23. Retrieved from http://www. taishukan.co.jp/gcdroom/gcd_tsuushin/pdf34/eit3409_21204.pdf

Taishūkan (2006, November). Midashigo ranku no minaoshi ni tsuite [On the revision of headword rankings]. G.C.D. Eigo Tsüshin, no. 40, p. 17. Retrieved from http://www.taishukan.co.jp/gcdroom/gcd_tsuushin/pdf40/GCD40ALL.pdf

Taishūkan (2009, November). Ei-wa jiten no midashigo sentei to juuyoudo ranku hyouji [English-Japanese dictionary headword selection and importance rank indicators]. G.C.D. Eigo Tsüshin, no. 46, pp. 12-33. Retrieved from http://www.taishukan.co.jp/gcdroom/gcd_tsuushin/pdf46/GCD46ALL.pdf

Taylor, I., \& Taylor, M. M. (1983). The psychology of reading. New York, NY: Academic Press.

Van Zeeland, H., \& Schmitt, N. (2013). Lexical coverage in L1 and L2 listening comprehension: The same or different from reading comprehension? Applied Linguistics, 34, 457-479. 